Res., Soc. Dev. 2019; 8(2):e3582782

ISSN 2525-3409 | DOI: http://dx.doi.org/10.33448/rsd-v8i2.782

Análise da eficiência dos gastos públicos com educação básica: um estudo na microrregião

\title{
Borborema Potiguar-RN
}

Analysis of the efficiency of public expenditure with basic education: a study in the Borborema Potiguar-RN microregion

Análisis de la eficiencia del gasto público con educación básica: un estudio en la microrregión Borborema Potiguar-RN

Matheus Cortês Dantas

Universidade Federal do Rio Grande do Norte, Brasil

E-mail: matheuscortes95@gmail.com

Márcio Vieira da Silva

ORCID: https://orcid.org/0000-0002-3427-251X

Universidade Federal do Rio Grande do Norte, Brasil

E-mail: vierimarcio@gmail.com

Recebido: 16/11/2018 | Revisado: 25/11/2018 | Aceito: 02/12/2018 | Publicado: 02/12/2018

\section{Resumo}

O presente estudo visa mensurar a eficiência da aplicação dos recursos públicos na educação básica feita pelos municípios da Borborema Potiguar-RN, o estudo teve como foco os anos iniciais do Ensino Fundamental. A metodologia aplicada para calcular a eficiência relativa dos 9 municípios da microrregião da Borborema Potiguar foi a Análise Envoltória de Dados (DEA). Nesta análise foram utilizados dados secundários como o gasto per capita aluno, quantidade de matrículas do censo escolar, média de alunos por turma, taxa de distorção idade-série, notas da Prova Brasil nas disciplinas de matemática e português. Os dados foram obtidos através dos sites do Instituto Nacional de Estudos e Pesquisas Educacionais Anísio Teixeira (INEP), Fundo Nacional de Desenvolvimento da Educação (FNDE), Sistema de Informações sobre Orçamentos Públicos em Educação (SIOPE) e Instituto Brasileiro de Geografia e Estatística (IBGE). A análise foi realizada no período de 2009 a 2015. Os resultados das análises mostraram que, em 2009, apenas 22,22\% dos municípios foram eficientes. Nos anos 2010 e 2011 o número de municípios considerados eficientes duplicou, resultando um total de 4 municípios. No biênio 2012/2013 o percentual de municípios que estiveram inseridos na fronteira de eficiência relativa permaneceu o mesmo, assim como nos últimos anos da pesquisa, 2014 e 2015. Os resultados desta pesquisa auxiliam em melhores tomadas de decisões no âmbito educacional por parte de seus gestores, tendo em vista verificações necessárias naqueles municípios, nos quais possuam eficiência inferior aos demais, sob o aspecto de alocação de recursos e de desempenho educacional.

Palavras-chaves: Gestão Pública, Ensino, Metodologia, Municípios. 


\section{Abstract}

The present study aims to measure the efficiency of the application of public resources in basic education made by Borborema Potiguar-RN municipalities, the study focused on the initial years of Elementary School. The methodology used to calculate the relative efficiency of the 9 municipalities of Borborema Potiguar micro-region was Data Envelopment Analysis (DEA). In this analysis we used secondary data such as per capita student expenditure, number of school census enrollments, average class size per pupil, age-grade distortion rate, Brazilian Proficiency in Mathematics and Portuguese subjects. The data were obtained through the websites of the National Institute of Educational Studies and Research Anísio Teixeira (INEP), National Fund for Educational Development (FNDE), Information System on Public Budgets in Education (SIOPE) and Brazilian Institute of Geography and Statistics (IBGE). The analysis was carried out in the period from 2009 to 2015. The results of the analyzes showed that in 2009, only $22.22 \%$ of the municipalities were efficient. In 2010 and 2011 the number of municipalities considered efficient doubled, resulting in a total of 4 municipalities. In the biennium 2012/2013, the percentage of municipalities that were included in the relative efficiency frontier remained the same, as in the last years of the survey, 2014 and 2015. The results of this research help in better decision-making in the educational scope of its managers, in view of necessary checks in those municipalities, in which they are less efficient than others, under the aspect of resource allocation and educational performance

Keywords: Public Management, Teaching, Methodology, Municipalities.

\section{Resumen}

El presente estudio apunta a medir la eficiencia de la aplicación de los recursos públicos en la educación básica hecha por los municipios de Borborema Potiguar-RN, el estudio tuvo como foco los años iniciales de la Enseñanza Fundamental. La metodología aplicada para calcular la eficiencia relativa de los 9 municipios de la microrregión de Borborema Potiguar fue el Análisis Envoltorio de Datos (DEA). En este análisis se utilizó datos secundarios como estudiante gasto per cápita, cantidad de la matrícula censo escolar, el tamaño promedio de las clases, la tasa de grado de edad, toma nota de la Prueba Brasil en matemáticas y portugués. Los datos fueron obtenidos a través de los sitios del Instituto Nacional de Estudios e Investigaciones Educativas Anísio Teixeira (INEP), Fondo Nacional de Desarrollo de la Educación (FNDE), Sistema de Información sobre Presupuestos Públicos en Educación (SIOPE) e Instituto Brasileño de Geografía y Estadística (SIOPE) IBGE). El análisis se realizó en el período de 2009 a 2015. Los resultados de los análisis mostraron que en 2009 sólo el 22,22\% de los municipios fueron eficientes. En los años 2010 y 2011 el número de municipios considerados eficientes se duplicó, resultando un total de 4 municipios. En el 
bienio 2012/2013 el porcentaje de municipios que estuvieron insertados en la frontera de eficiencia relativa permaneció igual, como en los últimos años de la encuesta, 2014 y 2015. Los resultados de esta investigación ayudan en mejores tomas de decisiones en el ámbito educativo por parte de sus los gestores, teniendo en cuenta verificaciones necesarias en aquellos municipios, en los cuales poseían eficiencia inferior a los demás, bajo el aspecto de asignación de recursos y de desempeño educativo.

Palabras claves: Gestión Pública, Enseñanza, Metodología, Municipios.

\section{Introdução}

A alocação de recursos limitados, por meio da qual busca-se atender as necessidades ilimitadas da sociedade, corresponde a um dos principais objetivos da economia. Aliando-se a isso, a administração pública, por sua vez, tem como um dos seus objetivos, a eficiência no emprego dos gastos públicos.

Nessa perspectiva, o equilíbrio entre recursos públicos investidos e resultados de qualidade nos serviços oferecidos se torna fundamental para a gestão pública, sobretudo em períodos de crises financeiras, sendo assim, a otimização da aplicação destes investimentos proporciona retorno ótimo a recursos escassos, que é o objetivo central de qualquer gestão responsável.

Estudos apontam que a educação tem se tornado uma área de alta relevância para a sociedade, visto que sua colaboração é o principal percursor no crescimento tanto do desenvolvimento social quanto do desenvolvimento econômico de um determinado lugar. Dentre os principais benefícios que a educação pode gerar, destaca-se a redução de vários problemas sociais, como a diminuição de criminalidade, o aumento do mercado de trabalho, a redução de desigualdades sociais, entre outros.

Segundo Schafranski (2005), a educação por meio de suas teorias e práticas, funcionam como componente primordial capaz de produzir e desenvolver melhores condições científicas, políticas, econômicas e culturais dentro da sociedade. Já na visão de Matta (2005, p.121) a educação:

[...] tem basicamente três funções: 1] em primeiro lugar, a educação é um forte elemento massificador e uniformizador, o que garante a ampliação dos padrões de consumo; 2] além disso, ela vai facilitar o controle social, já que os comportamentos, desejos, atitudes, também são massificados; 3] por fim, ela deve aprimorar as habilidades profissionais dos trabalhadores, ampliando sua eficiência e produtividade, o que servirá para alimentar as máquinas produtivas da burguesia. 


\section{Res., Soc. Dev. 2019; 8(2):e3582782}

ISSN 2525-3409 | DOI: http://dx.doi.org/10.33448/rsd-v8i2.782

Neste senário o sistema educacional brasileiro vem sofrendo nos últimos anos diversos avanços tais como melhoria no acesso ao ensino, criação do Fundo de Manutenção e Desenvolvimento do Ensino Fundamental e de Valorização do Magistério - Fundef, melhorias no Ensino de Jovens e Adultos-EJA, investimento em infraestrutura, esforços para o aumento do acesso à tecnologia, melhoria nas formas de inclusão, mudanças na legislação da Educação no Campo entre outras. Por outro lado, ainda há muito o que fazer, sobretudo no que diz respeito a permanência e ao sucesso do aluno. Assim, torna-se relevante o entendimento da relação entre o investimento em educação e o desempenho alcançado pelos alunos, uma vez que o planejamento de políticas educacionais como o planejamento de qualquer política pública é uma matéria sujeita a constantes revisões e ajustes, decorrentes da limitada capacidade dos entes governamentais de prever, com exatidão, cenários econômicos num horizonte de tempo muito amplo. Contudo, a demarcação de diretrizes para se contornar atrasos históricos do programa educacional brasileiro, que emperram o desenvolvimento econômico, é imprescindível e justifica o planejamento público (SOBREIRA; CAMPOS, 2008).

Este estudo está justificado uma vez que, existe uma preocupação constante com a destinação eficiente dos recursos públicos para a população brasileira, de forma que se torna necessário por parte dos gestores públicos, a prestação de serviços que atenda às demandas básicas da sociedade de maneira que consiga associar a redução de custos sem alterar a qualidade de serviço oferecido (SOUZA; ANDRADE; SILVA, 2015).

Conforme Rosano-Peña, Albuquerque e Marcio (2012), embora tenha havido melhorias dos últimos anos na educação pública brasileira, o ensino fundamental vem sendo bastante questionado quanto à sua qualidade e eficiência. Logo, a grande questão que se coloca é como impulsionar a qualidade do ensino nas escolas públicas brasileiras diante de um contexto de escassez e maior necessidade de racionalidade e eficiência na utilização dos recursos disponíveis.

Assim, a análise do estudo foi voltada para os municípios de pequeno porte I da microrregião Borborema Potiguar-RN. A escolha destes municípios torna-se admissível devido à quase ausência de estudos que medem a eficiência dos gastos públicos com educação básica no Rio Grande do Norte. Além disso, 15 dos 16 municípios da microrregião em estudo são classificados como municípios de pequeno porte I, isto é, municípios com população até 20.000 habitantes conforme o disposto na Política Nacional de Assistência Social - PNAS/2004 (2005). A referente pesquisa foi realizada em 9 municípios de pequeno porte I, os demais municípios da microrregião não foram analisados devido à insuficiência de dados.

Baseando-se neste contexto o referente estudo buscou compreender qual o nível de eficiência entre o investimento em educação básica e os resultados alcançados na Prova Brasil e no IDEB pelos municípios da microrregião da Borborema Potiguar - RN, entre os anos de 2009 a 2015.

Para alcançar seus objetivos esta pesquisa usou a metodologia Análise Envoltória de Dados (DEA) para mensurar a eficiência dos gastos públicos com educação básica, nas séries iniciais do 
ensino fundamental, da microrregião Borborema Potiguar-RN. Tal mensuração é pertinente, uma vez que analisada, limites de eficiência são formados possibilitando detectar ocorrências de baixos níveis de eficiência. Logo, municípios constatados menos eficientes poderão aperfeiçoar o desempenho, de modo que apliquem os recursos de maneira mais eficiente sem elevar a quantidade de capital financeiro.

\section{Metodologia}

A pesquisa, de acordo com a sua natureza, é classificada em pesquisa básica. Segundo Zanella (2012, p.70), este tipo de pesquisa "preocupa-se com o desenvolvimento do conhecimento pelo prazer de conhecer e evoluir cientificamente". Nesse sentido, Prodanov e Freitas (2013) apontam como finalidade desta pesquisa a geração de novos conhecimentos essenciais para a evolução da ciência sem aplicação prática prevista, envolvendo assim, verdades e interesses universais.

$\mathrm{Na}$ busca de conseguir atingir os objetivos, a metodologia utilizada na pesquisa, quanto aos fins, é descritiva. Como caracteriza Vergara (2007, p.49) "a pesquisa descritiva expõe características de determinada população ou de determinado fenômeno. [...] Não tem compromisso de explicar os fenômenos que descreve, embora sirva de base para tal explicação".

Quanto aos meios de investigação, a pesquisa é caracterizada como bibliográfica. Bibliográfica porque foram utilizados diversos materiais científicos disponíveis ao público, como artigos científicos, livros, revistas, índices, dados, orçamentos públicos já publicados. Segundo Vergara (2007), a pesquisa bibliográfica consiste no estudo sistematizado elaborado por meio de material publicado em livros, revistas, jornais, redes eletrônicas, entre outros, tratando-se assim, de materiais, seja qual for, disponíveis para todos os públicos. Em suma, o referido autor ressalta que o material publicado pode ser tanto de fonte primária quanto de fonte secundária.

Com relação a forma de abordagem, a pesquisa é quantitativa, pois foram coletados dados numéricos para a sua realização. Para Zanella (2012), este tipo de pesquisa se caracteriza pela utilização de instrumentos estatísticos na coleta e na análise dos dados, onde tem como objetivo mensurar relações entre as variáveis. Nessa perspectiva, Zanella (2006, p.97) salienta que "o método quantitativo se preocupa com representatividade numérica, isto é, com a medição objetiva e a quantificação dos resultados".

A ferramenta utilizada na pesquisa para medir a eficiência na esfera educacional consiste na Análise Envoltória de Dados (Data Envelopment Analysis - DEA).

\subsection{Análise Envoltória de Dados - DEA}

De acordo com Façanha e Marinho (2001), a DEA refere-se a uma metodologia que vem demonstrando ser tanto aconselhável como utilizável para avaliar organizações complexas, que, como umas de suas características, consiste em produzir outputs múltiplos (produtos) a partir de inputs múltiplos (insumos), assim como fazer uma comparação avaliativa dessas organizações sem se recorrer a padrões preestabelecidos de eficiência. 
Conforme caracteriza Casado (2007), a DEA consiste numa técnica não-paramétrica na qual faz uso de uma programação matemática com o intuito de formar fronteiras de produção de unidades produtivas, chamadas de Unidades Tomadoras de Decisão (Decision Making Units - DMU's), onde estas por sua vez, utilizam processos tecnológicos afins com propósito de converter múltiplos insumos em múltiplos produtos.

Em outras palavras, A DEA incide na busca pela melhor DMU dentre as DMU's analisadas, isto é, a metodologia DEA procura medir o maior desempenho de cada uma das DMU's referentes as demais. Contudo, deve-se considerar que é necessário que todas elas possuam características semelhantes dentro de um determinado grupo ou classificação.

A origem da Análise Envoltória de Dados (DEA) iniciou na década de 1970, a partir do trabalho elaborado por Charnes, Cooper, Rhodes no ano de 1978. Trabalho este que teve como proposta comparar a eficiência das escolas públicas americanas por meio de um programa de acompanhamento de alunos carentes. $\mathrm{O}$ intuito dessa pesquisa foi verificar e comparar o desempenho das escolas que participavam com as escolas que não participavam do programa.

Quanto a aplicação do DEA, é necessário fazer uma escolha: optar por um modelo que é orientado a outputs (produtos), onde se obtém o máximo nível de outputs mantendo os inputs (insumos) fixos. Ou escolher outro modelo, este orientado a inputs, que visa a obter um menor uso de inputs dado o nível dos outputs.

$$
\operatorname{Max} h_{\circ}=\sum_{r=1}^{m} u_{r} y_{r o}
$$

Sujeito a

$$
\begin{aligned}
& \sum_{i=1}^{n} v_{i} x_{i o}=1 \\
& \sum_{r=1}^{m} u_{i} y_{r j} \leq \sum_{i=1}^{n} v_{i} x_{i j} \quad j=1, \ldots, o_{,} \ldots, N
\end{aligned}
$$$$
u_{r}, v_{i} \geq 0 \quad r=1, \ldots, m ; \quad i=1, \ldots, n
$$

Onde

$y=$ produtos,$x=$ insumos $e u, v=$ pesos

A partir disso, o DEA dispõe de dois modelos clássicos de cálculos. O primeiro modelo é o CCR ou CRS, desenvolvido por Charnes, Cooper e Rhodes em 1978. E o segundo modelo é o BCC ou VRS, criado por Banker, Charnes e Cooper em 1984. As siglas referem-se as letras iniciais dos sobrenomes dos autores fundadores dos modelos, assim como também podem ser classificados de 
acordo com o retorno da escala, isto é, constante (Constant Return to Scale - CRS) ou variável (Variable Return to Scale - VRS).

Do ponto de vista de Casado (2007, p. 66), o modelo denominado CCR “[...] foi concebido inicialmente como um modelo orientado à entrada (input) e trabalha com retorno constante de escala (CRS), isto é, qualquer variação nas entradas (inputs) produz variação proporcional nas saídas (outputs)", como neste trabalho usamos o modelo BCC, omitiremos as equações referentes ao modelo CCR.

Casado (2007) diz logo em sequência que o modelo BCC, diferente do modelo CCR, emprega o retorno variável de escala (VRS), com o propósito de conter problemas presentes em circunstâncias de competição imperfeita. A aplicação desse modelo advém no momento em que ocorrem Retornos Variáveis de Escala, independentemente de serem crescentes, decrescentes ou constantes.

Segundo Carvalho (2014) a modelo DEA CCR (orientado para inputs e outputs) segue a programação linear representada nas equações:

$$
\operatorname{Max} h_{\circ}=\sum_{r=1}^{m} u_{r} y_{r o}
$$

\section{Sujeito a}

$$
\begin{aligned}
& \sum_{i=1}^{n} v_{i} x_{i o}=1 \\
& \sum_{r=1}^{m} u_{i} y_{r j} \leq \sum_{i=1}^{n} v_{i} x_{i j} \quad j=1, \ldots o, \ldots, N \\
& u_{r}, v_{i} \geq 0 \quad r=1, \ldots, m ; \quad i=1, \ldots, n \\
& \text { Onde }
\end{aligned}
$$

$y=$ produtos $x=$ insumos $e u, v=$ pesos

A DEA embora tenha sido criada para avaliar a eficiência voltada para a área da educação, com o passar dos anos, a ferramenta veio passando por mudanças e aperfeiçoamentos, e se desenvolvendo rapidamente com modelos que cada vez mais utilizados e aplicados em outras áreas, tais como: saúde, comércio, finanças, agricultura, setores públicos, entre outros.

Peña (2008) afirma que a DEA vem sendo utilizada de forma mais abrangente em outras áreas a DEA tem sido utilizada com êxito no estudo da eficiência do setor público e em organizações sem fins lucrativos. Desse modo, ela vem sendo usada para comparar departamentos educacionais, estabelecimentos de saúde, prisões, produção agrícola, instituições financeiras, países, forças armadas, esportes, transporte, redes de restaurantes, franquias, cortes de justiça, instituições culturais, entre outros. 
ISSN 2525-3409 | DOI: http://dx.doi.org/10.33448/rsd-v8i2.782

Por meio da metodologia DEA empregado o modelo CCR, no qual teve orientação para output devido possibilitar a inspeção da maximização da produção tendo como base a correção nos níveis de insumo.

A microrregião Borborema Potiguar é formada por 16 municípios, na qual 15 deles são considerados municípios de pequeno porte I e apenas 1 é considerado de pequeno porte II. Em relação à área de estudo e em conformidade com a população do Censo 2010 realizado pelo Instituto Brasileiro de Geografia e Estatística (IBGE), 9 dos 15 municípios de pequeno porte I da microrregião Borborema Potiguar-RN foram analisados, compondo assim o grupo de DMU's. Houve uma remoção de 6 municípios de pequeno porte I e 1 de pequeno porte II por motivos de escassez de dados e diferenciação de porte populacional, respectivamente, tornando impossível a comparação com o restante dos municípios.

Os dados coletados e utilizados na DEA foram dados secundários. Para Zanella (2006, p.99), "dados secundários são os dados que já foram coletados, tabulados, ordenados e, algumas vezes, já analisados".

Diante disso, os dados foram obtidos por meio dos sites do Instituto Nacional de Estudos e Pesquisas Educacionais Anísio Teixeira (INEP), Fundo Nacional de Desenvolvimento da Educação (FNDE), Sistema de Informações sobre Orçamentos Públicos em Educação (SIOPE) e IBGE. Os referidos dados correspondem aos anos de 2009 a 2015 e, referem-se a indicadores educacionais, são eles: notas da Prova Brasil na disciplina de matemática e de português, média de alunos por turma, taxa de distorção idade-série, média da despesa per capita dos alunos e quantidade de matrículas do censo escolar, todos relacionados ao ensino fundamental.

Para descobrir a média da despesa per capita dos alunos foi feito um cálculo por meio da divisão entre o valor das despesas pagas dos alunos pelo número de matrículas realizadas no mesmo período.

Nesta pesquisa, quanto aos inputs (insumos), os dados coletados e analisados foram: média da despesa per capita dos alunos do ensino fundamental dos anos iniciais nos biênios; média de alunos por turma do ensino fundamental dos anos iniciais nos biênios; taxa de distorção idade-série anos iniciais nos biênios. Quanto aos outputs (produtos), os dados coletados e analisados consistiram nas notas da Prova Brasil na disciplina de matemática e nas notas da Prova Brasil na disciplina de português.

É importante destacar que a Prova Brasil é aplicada a cada 2 anos e em anos ímpares. Por outro lado, tanto os investimentos quanto os indicadores educacionais são registrados anualmente. Nessa perspectiva, este estudo analisou além do ano da realização da Prova Brasil, o ano antecessor, formando assim os chamados biênios. Houve uma exceção para o ano 2009, pois em seu ano antecessor foi constatado escassez de dados, e assim, 2009 foi o único período da presente pesquisa que utilizou somente os inputs do referido ano, conforme apresenta o quadro a seguir: 
Res., Soc. Dev. 2019; 8(2):e3582782

ISSN 2525-3409 | DOI: http://dx.doi.org/10.33448/rsd-v8i2.782

QUADRO 1 - Período para a medição da eficiência

\begin{tabular}{|c|c|}
\hline $\begin{array}{c}\text { Período da variável } \\
\text { input }\end{array}$ & $\begin{array}{c}\text { Período da variável } \\
\text { output }\end{array}$ \\
\hline 2009 & 2009 \\
\hline $2010-2011$ & 2011 \\
\hline $2012-2015$ & 2013 \\
\hline $2014-2015$ & 2015 \\
\hline
\end{tabular}

Fonte: Elaborado pelo autor.

Quanto à análise dos dados, após a coleta, os mesmos foram inseridos na ferramenta DEA, e posteriormente analisados, interpretados e representados em quadros para uma melhor compreensão.

\section{Resultados e discursões}

$\mathrm{Na}$ busca de um melhor entendimento apresentaremos primeiro análise do ranking de eficiência das DMU's, segundo seus respectivos escores.

\subsection{Ranking dos escores de eficiência}

A identificação do nível de eficiência das DMU's permitiu a elaboração de um ranking no qual os municípios são classificados de maneira crescente como mais eficiente. A fronteira de eficiência relativa (padrão) indica as DMU's eficientes nos anos do estudo, isto é, as DMU's que atingiram o escore máximo (1). Na fronteira invertida, estão localizadas as DMU's não eficientes de tal modo que a DMU que estiver mais afastada dessa fronteira será mais eficiente.

A tabela a seguir apresenta os escores obtidos após a aplicação da metodologia DEA por meio do qual será possível elaborar o ranking das DMU's em relação à eficiência dos gastos públicos com educação nas séries iniciais do ensino fundamental referente aos municípios em todos os períodos da pesquisa.

TABELA 1 - Ranking geral dos escores de eficiência das DMU's

\begin{tabular}{|c|c|c|c|c|c|c|c|}
\hline \multicolumn{4}{|c|}{ Escore de eficiência em 2009} & \multicolumn{4}{|c|}{ Escore de eficiência entre 2010 e 2011} \\
\hline Ordem & $\begin{array}{c}\text { DMU's } \\
\text { (Municípios) }\end{array}$ & $\begin{array}{l}\text { Fronteira } \\
\text { Padrão }\end{array}$ & $\begin{array}{l}\text { Fronteira } \\
\text { Invertida }\end{array}$ & Ordem & $\begin{array}{c}\text { DMU's } \\
\text { (Municípios) }\end{array}$ & $\begin{array}{c}\text { Fronteira } \\
\text { Padrão }\end{array}$ & $\begin{array}{l}\text { Fronteira } \\
\text { Invertida }\end{array}$ \\
\hline $1^{\circ}$ & Lagoa de Velhos & 1,000000 & 0,766499 & $1^{\circ}$ & São Tomé & 1,000000 & 0,828976 \\
\hline $2^{\circ}$ & São Tomé & 1,000000 & 0,780140 & $2^{\circ}$ & Sítio Novo & 1,000000 & 0,879714 \\
\hline $3^{\circ}$ & Tangará & 0,952615 & 1,000000 & $3^{\circ}$ & Tangará & 1,000000 & 0,962404 \\
\hline $4^{\circ}$ & Japi & 0,874148 & 0,893847 & $4^{\circ}$ & Lagoa de Velhos & 1,000000 & 1,000000 \\
\hline $5^{\circ}$ & Campo Redondo & 0,836035 & 1,000000 & $5^{\circ}$ & Jaçanã & 0,987580 & 0,953014 \\
\hline $6^{\circ}$ & Sítio Novo & 0,816401 & 0,990983 & $6^{\circ}$ & Japi & 0,944865 & 0,970516 \\
\hline $7^{\circ}$ & Ruy Barbosa & 0,796734 & 0,985814 & $7^{\circ}$ & Lajes Pintadas & 0,901457 & 1,000000 \\
\hline $8^{\circ}$ & Lajes Pintadas & 0,778966 & 1,000000 & $8^{\circ}$ & Ruy Barbosa & 0,873341 & 0,948478 \\
\hline $9^{\circ}$ & Jaçanã & 0,764627 & 1,000000 & $9^{\circ}$ & Campo Redondo & 0,852959 & 1,000000 \\
\hline \multicolumn{4}{|c|}{ Escore de eficiência entre 2012 e 2013} & \multicolumn{4}{|c|}{ Escore de eficiência entre 2014 e 2015} \\
\hline
\end{tabular}


Res., Soc. Dev. 2019; 8(2):e3582782

ISSN 2525-3409 | DOI: http://dx.doi.org/10.33448/rsd-v8i2.782

\begin{tabular}{|c|c|c|c|c|c|c|c|} 
Ordem & $\begin{array}{c}\text { DMU's } \\
\text { (Municípios) }\end{array}$ & $\begin{array}{c}\text { Fronteira } \\
\text { Padrão }\end{array}$ & $\begin{array}{c}\text { Fronteira } \\
\text { Invertida }\end{array}$ & Ordem & $\begin{array}{c}\text { DMU's } \\
\text { (Municípios) }\end{array}$ & $\begin{array}{c}\text { Fronteira } \\
\text { Padrão }\end{array}$ & $\begin{array}{c}\text { Fronteira } \\
\text { Invertida }\end{array}$ \\
\hline $1^{\mathbf{o}}$ & Tangará & 1,000000 & 0,853704 & $1^{\mathbf{o}}$ & Sítio Novo & 1,000000 & 0,846009 \\
\hline $2^{\mathbf{o}}$ & Sítio Novo & 1,000000 & 0,858123 & $2^{\mathbf{o}}$ & Ruy Barbosa & 1,000000 & 0,891165 \\
\hline $3^{\mathbf{o}}$ & Japi & 1,000000 & 0,943366 & $3^{\mathbf{o}}$ & Tangará & 1,000000 & 0,928959 \\
\hline $4^{\mathbf{o}}$ & Lagoa de Velhos & 1,000000 & 1,000000 & $4^{\mathbf{o}}$ & Lagoa de Velhos & 1,000000 & 1,000000 \\
\hline $5^{\mathbf{o}}$ & São Tomé & 0,943065 & 0,941590 & $5^{\mathbf{o}}$ & São Tomé & 0,947209 & 0,940555 \\
\hline $6^{\mathbf{0}}$ & Ruy Barbosa & 0,933979 & 0,913110 & $6^{\mathbf{o}}$ & Japi & 0,935128 & 0,998882 \\
\hline $7^{\mathbf{o}}$ & Lajes Pintadas & 0,878810 & 1,000000 & $7^{\mathbf{o}}$ & Lajes Pintadas & 0,915456 & 0,942634 \\
\hline $8^{\mathbf{o}}$ & Campo Redondo & 0,878632 & 1,000000 & $8^{\mathbf{o}}$ & Jaçanã & 0,883448 & 1,000000 \\
\hline $9^{\mathbf{o}}$ & Jaçanã & 0,870381 & 1,000000 & $9^{\mathbf{o}}$ & Campo Redondo & 0,789930 & 1,000000 \\
\hline
\end{tabular}

Fonte: Indicadores de Eficiência obtidos pela DEA. Elaboração: Autor.

Em 2009, Lagoa de Velhos foi a mais eficiente dentre todas as DMU's. O município de Jaçanã teve a pior atuação no mesmo período em decorrência do baixo rendimento em eficiência relacionado a investimentos e qualidade de ensino, apresentando um (índice de eficiência) IE de 0,764627 na fronteira padrão. Com $\mathrm{R} \$ 3.413,37$, a despesa per capita dos alunos de Jaçanã foi a maior dentre os municípios, porém o desempenho na Prova Brasil não ocorreu na mesma proporção, logo essa circunstância destaca-se como principal fator desse mau desempenho.

Nos períodos seguintes, a partir dos escores contidos na fronteira padrão, foi verificado um aumento de DMU's consideradas eficientes, onde 4 dos 9 municípios analisados estiveram inseridos na fronteira de eficiência em cada biênio, em outras palavras, a quantidade de DMU's eficientes duplicou comparando-o ao primeiro período analisado.

Entre os anos 2010 e 2011 foi constatado que dentre os 4 municípios vistos como eficientes, São Tomé apresentou o melhor desempenho, e da segunda colocação em 2009 alcançou o topo do ranking no biênio 2010 - 2011. Por outro lado, Lagoa de Velhos, a DMU referência no ano anterior, continuou na linha de eficiência da fronteira padrão, porém obteve o pior resultado na fronteira invertida dentre as DMU's eficientes e ficou na $4^{a}$ posição. A partir da análise na fronteira padrão, o município de Campo Redondo foi evidenciado como o pior IE dentre todas as DMU's. Diversos fatores comprovam isso, destaca-se a média da taxa de distorção idade-série no biênio, onde com $16,35 \%$, teve a menor taxa em relação às demais DMU's e consequentemente poderia ter aproveitado esse fator positivo para melhorar sua qualidade de ensino. Além disso, as notas de matemática e de português da Prova Brasil do referido município estiveram entre as mais baixas em relação aos demais municípios, contribuindo assim para a ocupação do último lugar no ranking do biênio.

No período seguinte, composto pelos anos 2012 e 2013, verifica-se que o município de Tangará apresentou o IE bem próximo ao de Sítio Novo. Com uma pequena diferença de eficiência na Fronteira Invertida, 0,004419, Tangará foi tida como a DMU mais eficiente do biênio. Ao contrário de Tangará, Jaçanã apresentou baixo desempenho e foi classificada mais uma vez como a DMU com piores resultados sem conseguir atingir seus objetivos esperados. $\mathrm{O}$ fato de possuir como inputs, no 
biênio citado, a menor média da taxa de distorção idade-série, $14,25 \%$, e uma baixa média de aluno por turma entre as DMU's, 18,25, Jaçanã não converteu esses fatores em qualidade de ensino, resultando na posição mais baixa do ranking.

O último biênio da análise identificou Sítio Novo como o município que obteve a maior eficiência sobre os demais municípios. Destaca-se o município de Ruy Barbosa, que após ocupar posições baixas nos anos anteriores, foi avaliado como eficiente e ocupou o $2^{\circ}$ lugar no ranking do biênio 2014 e 2015, fatores como a $2^{\mathrm{a}}$ menor média de despesa per capita dos alunos, $\mathrm{R} \$ 4.975,93$, e as maiores notas da Prova Brasil em comparação com as demais DMU's, 208,53 em matemática e 197,06 em português, contribuíram fortemente para esse escore. Campo Redondo, por sua vez, ocupou a última posição do ranking e foi apontado como o município que conteve o pior rendimento em termos de eficiência do biênio. Mesmo com a $2^{\mathrm{a}}$ maior média de despesa per capita dos alunos, $\mathrm{R} \$$ 5.710,84, a referida DMU não conseguiu transformar os recursos financeiros em resultados expressivos e eficientes.

Diante desses resultados, nota-se que Jaçanã e Campo Redondo foram as DMU's consideradas menos eficientes em todos os anos da pesquisa, destacando o período inicial e final como os piores rendimentos de ambos os municípios, apresentando um IE inferior a $80 \%$ do valor máximo, nessa ordem.

\section{Considerações finais}

Os resultados obtidos e as observações apresentadas ao longo deste trabalho sobretudo no âmbito da utilização dos recursos públicos na educação e qual sua relação com os resultados obtidos pelos índices educacionais, contribuem com o surgimento de discussões na direção da otimização do financiamento público da educação, já a educação corresponde a uma área significativa para a sociedade em termos de desenvolvimento social e econômico tendo em vista sua capacidade de reduzir problemas sociais tais como criminalidade e desigualdade econômica e social, além da sua relevância para o crescimento no mercado de trabalho.

Foi constatado que a eficiência dos municípios não está ligada diretamente apenas ao fator econômico baseado em despesas com alunos, elementos como médias de alunos por turmas e taxa de distorção idade-série também foram significativos nesse estudo. Dessa forma, entende-se que a gestão como um todo é primordial na busca de resultados eficientes, tomando decisões corretas em cada situação detectada.

Os objetivos do estudo foram atingidos em razão das análises comparativas entre os municípios, da mensuração dos escores de eficiência e da identificação de cada DMU referência em cada período. Em função disso foram utilizados dados relacionados ao ensino fundamental referentes a despesas pagas, quantidade de matrículas, média de alunos por turma, taxa de distorção idade-série e notas da Prova Brasil. 
As limitações da pesquisa consistem na quantidade de municípios analisados da microrregião Borborema Potiguar-RN que embora seja composta por 16 municípios, foram avaliados apenas 9 municípios, os demais municípios foram removidos por falta de dados e diferenciação de porte populacional. Além disso, só foi possível a análise dos anos iniciais do ensino fundamental por motivos de insuficiências de dados referentes aos anos finais de algumas DMUs, inviabilizando resultados mais globais e completos.

Recomenda-se que pesquisas futuras sejam realizadas a fim de analisar profundamente a eficiência dos dispêndios públicos com educação básica, ampliando a quantidade de municípios a serem avaliados, utilizando dados dos anos iniciais e anos finais do ensino fundamental e empregando outros indicadores educacionais, de modo que gerem resultados mais abrangentes.

\section{Referências}

ANDRADE, Nilton de Aquino. Contabilidade pública na gestão municipal. São Paulo: Atlas, 2002. . Instituto Nacional de Estudos e Pesquisas Educacionais Anísio Teixeira - INEP. Cenário Educacional. Disponível em: <http://portal.inep.gov.br/cenario-educacional/>. Acesso em: $02 / 04 / 2018$. . Instituto Nacional de Estudos e Pesquisas Educacionais Anísio Teixeira - INEP. Indicadores Educacionais. Disponível em: <http://portal.inep.gov.br/indicadores-educacionais>. Acesso em: 30 set. 2017.

Instituto Nacional de Estudos e Pesquisas Educacionais Anísio Teixeira - INEP. Sistema de Consulta a Matrícula do Censo Escolar - 1997/2016. Disponível em: $<$ http://matricula.educacenso.inep.gov.br/>.

. Lei $\mathbf{n}^{0}$ 4.320, de 17 de março de 1964. Estatui Normas Gerais de Direito Financeiro para elaboração e controle dos orçamentos e balanço da União, dos Estados, dos Municípios e do Distrito Federal. Disponível em: <http://www.planalto.gov.br/ccivil_03/leis/L4320.htm>.

Política Nacional de Assistência Social PNAS/2004. Brasília, 2005. Disponível em: <http://www.mds.gov.br/webarquivos/publicacao/assistencia_social/Normativas/PNAS2004.pdf>.

Sistema de Informações sobre Orçamentos Públicos em Educação - SIOPE. Relatórios Municipais: Demonstrativo da Função Educação. Disponível em: <https://www.fnde.gov.br/siope/demonstrativoFuncaoEducacao.do>. 
CARVALHO, F. P. L. de et al. Eficiência econômico-financeira do setor de energia elétrica brasileiro nos anos 2010 e 2011. RIC - Revista de Informação Contábil, Pernambuco, v. 8, n. 1, p. 1-27, mar. 2014. Disponível em: <https://periodicos.ufpe.br/revistas/ricontabeis/article/view/8002/8073>.

CASADO, Frank Leonardo. Análise envoltória de dados: conceitos, metodologia e estudo da arte na educação superior. Revista Sociais e Humanas, Santa Maria, v. 20, n. 01, p. 59-71, jan./jun. 2007. Disponível em: <https://periodicos.ufsm.br/sociaisehumanas/article/viewFile/907/635>.

Cidade-Brasil: Microrregião Borborema Potiguar. Disponível em: http://www.cidadebrasil.com.br/microrregiao-da-borborema-potiguar.html

CHARNES, A.; COOPER, W. W.; RHODES, E. Measuring the efficiency of decision making units. European Journal of Operational Research, v. 2, n. 6, p. 429-444, 1978.

FAÇANHA, Luís Otávio; MARINHO, Alexandre. Instituições de ensino superior governamentais e particulares: avaliação comparativa de eficiência. Revista de Administração Pública, Rio de Janeiro, v. 35, n.6, p. 83-105, nov./dez. 2001. Disponível em: <http://bibliotecadigital.fgv.br/ojs/index.php/rap/article/viewFile/6416/5001>.

MATTA, Isabel. Psicologia do desenvolvimento e da aprendizagem. Lisboa: Universidade Aberta, 2005.

PEÑA, Carlos Rosano. Um modelo de avaliação da eficiência da administração pública através do método análise envoltória de dados (DEA). Revista de Administração Contemporânea, Curitiba, v. 12, n. 1, p. 83-106, jan./mar. 2008. Disponível em: <http://www.scielo.br/pdf/rac/v12n1/a05v12n1>.

PRODANOV, Cleber Cristiano; FREITAS, Ernani Cesar de. Metodologia do trabalho científico: métodos e técnicas da pesquisa e do trabalho acadêmico. 2. ed. Novo Hamburgo: Feevale, 2013. Disponível em: <http://docente.ifrn.edu.br/rodrigotertulino/disciplinas/2015.2/seminario-de-iniciacaocientifica/livro/e-book-metodologia-do-trabalho-cientifico/view>. Acesso em: 30 nov. 2017. 
ISSN 2525-3409 | DOI: http://dx.doi.org/10.33448/rsd-v8i2.782

ROSANO-PEÑA, C.; ALBUQUERQUE, P. H. M.; MARCIO, C. J. A eficiência dos gastos públicos em educação: evidências georreferenciadas nos municípios goianos. Economia Aplicada, São Paulo, v. 16, n. 3, p.421-443, 10 jul. 2012. Disponível em: 〈http://www.scielo.br/pdf/ecoa/v16n3/04.pdf〉.

SCHAFRANSKI, Márcia Derbli. A educação e as transformações da sociedade. Publ. UEPG Humanit. Sci., Appl. Soc. Sci., Linguist., Lett. Arts, Ponta Grossa, n. 13, p. 101-112, dez. 2005. Disponível em: <http://www.revistas2.uepg.br/index.php/humanas/article/view/550/549>.

SILVA, Ângelo Henrique Lopes da; NETO, Melchior Sawaya; GRANJA E BARROS, Fábio Henrique. Texto para discursão 2126 - Avaliação da Eficiência dos Centros de Referência de Assistência Social no Brasil. IPEA, Rio de Janeiro, ago. 2015. Disponível em: <https://craspsicologia.files.wordpress.com/2015/09/ipea.pdf>. Acesso em: 11 out. 2017.

SILVA, M. C.; SOUZA, F. J. V.; ARAÚJO, A. O. Análise da eficiência dos gastos públicos com educação nas capitais brasileiras. ConTexto, Porto Alegre, v. 13, n. 24, p. 7-21, maio/ago. 2013. Disponível em: <http://seer.ufrgs.br/index.php/ConTexto/article/view/31962/pdf>.

SOBREIRA, Rogério e CAMPOS, Bruno Cesar. Investimento público em educação fundamental e a qualidade do ensino: uma avaliação regional dos resultados do Fundef. Rev. Adm. Pública [online]. 2008, vol.42, n.2, pp.327-346. ISSN 0034-7612.

SOUZA, F. J. V.; ANDRADE, A. P. F.; SILVA, M. C. Eficiência na alocação de recursos públicos destinados ao ensino fundamental: Um estudo da sua relação com a condição financeira de municípios brasileiros. ConTexto, Porto Alegre, v. 15, n. 31, p. 81-99, set./dez. 2015. Disponível em: <http://seer.ufrgs.br/index.php/ConTexto/article/view/53971/pdf_60>.

VERGARA, Sylvia Constant. Projetos e relatórios de pesquisa em administração. 9 ed. São Paulo: Atlas, 2007.

ZANELLA, Liane Carly Hermes. Metodologia da pesquisa. Florianópolis: SEaD/UFSC, 2006. 144p. 